\title{
TINTERthesis
}

\section{VIOLÊNCIA DOMÉSTICA NO CAMPO: INEXISTENTE OU INVISÍVEL?}

Domestic violence in the countryside: inexistent or invisible?

\author{
Maria Eloá Gehlen \\ Doutora em Educação \\ Universidade Federal da Fronteira Sul, Laranjeiras do Sul, Brasil. \\ maria.gehlen@uffs.edu.br \\ (Dhttps://orcid.org/0000-0003-3802-9434 \\ Carolina Orquia Cherfem \\ Doutora em Ciências Sociais da Educação \\ Universidade Federal de Santa Catarina, Florianópolis, Brasil. \\ carolina.cherfem@ufsc.br \\ Dhttps://orcid.org/0000-0003-1482-7298
}

A lista completa com informações dos autores está no final do artigo

\section{RESUMO}

Este artigo indaga sobre a inexistência ou a invisibilidade da violência contra a mulher do campo, tendo como locus de pesquisa o município de Laranjeiras do Sul (PR). A metodologia utilizada se pauta em revisão bibliográfica e documental, além da vivência no Conselho Municipal dos Direitos da Mulher. Os resultados apontam para a invisibilidade da violência doméstica no campo, seja pela falta de informação, seja pelo patriarcado presente nas relações sociais, ou pelas dificuldades que as camponesas encontram para realizarem uma denúncia. Concluímos que se trata de uma violência silenciada, muitas vezes em número maior que na área urbana, considerando-se a proporção de habitantes.

PALAVRAS-CHAVE: Violência doméstica. Mulheres. Campo.

\section{ABSTRACT}

This article questions the inexistence or the invisibility of violence against women in countryside areas. Our research took place in the city of Laranjeiras do Sul, Brazil. In addition, its methodology consists of literature and documental review and for the experience in the municipal council of women's rights. The results lead us to the invisibility of domestic violence in the fields, motivated either because of the lack of information, the patriarchate present in social relations or the difficulties that peasant women face to report abuses. Our conclusion points out to a scenario of silenced violence, most of the times in a largest number that in to urban areas, considering the proportion of inhabitants.

KEYWORDS: Domestic Violence. Women Studies. Field.

\section{INTRODUÇÃO}

O tema da violência doméstica no campo ainda é incipiente no debate científico, contando com poucos registros entre as investigações acadêmicas. Destacam-se no debate as pesquisas de Lorenzoni $(2008,2020)$ e o artigo sobre a temática no livro "Feminismo Camponês Popular" (MEDRAZl et al, 2021), o qual apresenta, de um lado, diferentes relatos que ilustram as dificuldades das camponesas em romper com o silêncio da violência sofrida cotidianamente, de outro, busca contribuir com o fortalecimento da 
organização coletiva e das políticas públicas para avançar na resistência e no enfrentamento à discriminação, à opressão, à exploração e a todas as formas de violência contra as mulheres camponesas (LORENZONI, RODRIGUES, SANTOS, 2021). Igualmente em Silva (2020), encontra-se o debate do enfrentamento à violência pautado nos princípios agroecológicos, na construção da autonomia e na independência das mulheres camponesas.

O assunto também não encontra grande popularidade nas pautas das organizações e instituições sociais que atendem ao meio rural. No entanto, as ações de enfrentamento à violência vêm ganhando notoriedade entre os movimentos sociais do campo, sobretudo a partir do Movimento de Mulheres Camponesas (MMC) e dos setores de gênero do Movimento dos Trabalhadores Rurais Sem Terra (MST), os quais estão buscando dar visibilidade às diversas formas de opressão e violências sofridas pelas mulheres camponesas (CARISSIMI, 2013; MEDRAZI et al, 2021).

Nesse contexto, a pergunta que motivou esta investigação foi: as diferentes formas de violência doméstica contra as camponesas são inexistentes ou são, na verdade, invisibilizadas pelos familiares, pelos Sindicatos de Trabalhadores Rurais, pelas igrejas, pelas escolas, pelos clubes de mães, pelas autoridades municipais e estudais, pelas universidades, enfim, pela sociedade?

A metodologia utilizada para a investigação se utilizou de pesquisa bibliográfica e uma pesquisa documental, tendo como objetos e metodologia de análise os processos no Fórum de Laranjeiras do Sul, da Vara Criminal, para investigação dos processos de violência doméstica no campo; uma decisão recente da Sexta Turma do Superior Tribunal de Justiça (STJ), de 18/09/2019¹, além da legislação brasileira. Foram realizadas ainda pesquisas no Centro de Referência Especializado de Assistência Social (CREAS) do respectivo município, para verificar o número de atendimentos psicológicos às mulheres do campo. A pesquisa também contou com o registro de alguns encontros como rodas de conversa e palestras em escolas do campo e clubes de mães no meio rural.

O município de Laranjeiras do Sul se localiza na região sudoeste do estado do Paraná, com produção voltada à agricultura familiar, com destaque à produção de arroz, soja e leite. Os empregos são, em sua maioria, provenientes da agricultura, da administração pública, do comércio e de poucas indústrias. A região possui

${ }^{1}$ Revista Consultor Jurídico (2019). O número do processo não foi divulgado em razão de segredo de Justiça. 
assentamentos da reforma agrária, uma terra indígena e áreas quilombolas, sendo, portanto, propícia para a organização coletiva e camponesa.

No desenvolvimento de atividades nesses espaços, sobretudo por meio da participação de uma das autoras na Comissão Municipal dos Direitos da Mulher de Laranjeiras do Sul, foi possível verificar os boletins de ocorrências de violência doméstica na Delegacia de Polícia do município.

Ao pesquisarmos esses dados, verificamos índices elevados de denúncias na área considerada urbana, porém pouquíssimos registros vindos da zona rural, o que gerou uma inquietação e ampliou a hipótese da investigação: os casos de violências domésticas ocorridas no campo não existem ou são invisíveis?

A fim de problematizar tal inquietação e discorrer sobre esta hipótese, já denunciada pelos movimentos sociais, o artigo encontra-se dividido em cinco partes: primeiramente discute-se sobre a questão da violência como instrumento de controle das mulheres do campo; na segunda parte falaremos sobre o silenciamento da violência no campo, à luz da pesquisa realizada; na terceira parte buscaremos esclarecer os casos de violência a partir da lei Maria da Penha, relacionando os diferentes tipos de violência com a especificidade do campo; na quarta parte trataremos sobre a masculinidade tóxica que retroalimenta os casos de violência do campo. Por fim, nas considerações finais, será possível compreender a contradição entre o silenciamento e a invisibilidade da violência contra as mulheres no campo. Faz-se necessário a construção de uma rede de assistência social, de políticas públicas adequadas, além da organização coletiva camponesa para que esse ciclo seja rompido.

\section{A VIOLÊNCIA DOMÉSTICA COMO INSTRUMENTO DE CONTROLE DAS MULHERES NO CAMPO}

De modo a trabalhar a questão das mulheres com um foco local, escolhemos o município de Laranjeiras do Sul (PR), que tem sua produção prioritariamente voltada para a agricultura familiar, o que nos indica de antemão que há um trabalho de preservação e cultivo da terra, bem como de cuidados com a família e com os animais, realizados pelas mulheres. Em suas proximidades, existem assentamentos da reforma agrária, terra indígena e áreas quilombolas, sendo, portanto, uma região privilegiada para a organização camponesa e para a organização coletiva das mulheres. 
Nesses espaços foram realizadas, ao longo dos anos de 2018 e 2019, algumas atividades voltadas ao tema da violência doméstica, como palestras e rodas de conversa em escolas do campo e clubes de mães do meio rural, o que motivou a realização desta pesquisa. Cada vez que as rodas de conversas eram encerradas, alguém relatava um crime de violência doméstica em sua casa, na casa do vizinho ou de um parente no campo. Notamos, portanto, que no âmbito informal, as vivências, as observações e os diálogos a respeito dos crimes de violência doméstica saem do silenciamento, mas, como revelou a investigação, eles não são denunciados e, portanto, tornam-se invisíveis para o Estado e para a sociedade de modo geral.

Em nossa investigação consultamos o CREAS de Laranjeiras do Sul, o qual faz atendimento psicológico gratuito para mulheres vítimas de violência doméstica e faz parte da Rede de Proteção à Mulher. Constatamos que no ano de 2016 foram efetuados 27 atendimentos de violência doméstica, sendo 4 da zona rural; em 2017, foram atendidas 58 mulheres, sendo 5 da zona rural; e, no ano de 2018, foram atendidas 43 mulheres, sendo 1 da zona rural. Foram 128 atendimentos psicológicos de mulheres com histórico de violência doméstica em 3 anos no CREAS. Apenas 10 eram oriundas do meio rural, com um percentual de $7,82 \%$ das pacientes atendidas. Verifica-se que poucas camponesas procuram ou sabem da existência desse tipo de atendimento às mulheres vítimas de violência doméstica. Embora tal busca precise ser informada e estimulada, há um início de procura por redes de atendimento às mulheres do campo, entre os quais o CREAS se insere.

No entanto, muitas vezes os psicólogos e assistentes sociais atendem mulheres camponesas e percebem que há situação de violência doméstica, mesmo que esse não seja o motivo principal da procura por essas mulheres. A equipe do CREAS procura dialogar com elas, informá-las e auxiliá-las nas situações de violência doméstica. A procura das mulheres da zona rural pelo CREAS é menor que a das mulheres urbanas, visto que as primeiras não possuem muito acesso a transporte e meios de chegar ao CREAS, além de não possuírem a cultura de buscar auxílio dos psicólogos, serviços sociais oferecidos pelo Estado.

Conforme explicam Lorenzoni, Rodrigues e Santos (2021, p. 145), as camponesas sentem-se "pequenas" diante do problema e acabam silenciando as agressões sofridas, principalmente porque naturalizam a situação de dependência, de controle e de submissão existente na sociedade patriarcal. As autoras descrevem alguns relatos de mulheres vítimas de violência em que a situação geográfica do campo agrava a situação: 
"A mulher que mora no campo, ela tem a vida muito isolada. Se bater. Se gritar. Se chorar. Se espernear, ninguém ouve". É verdade! Por mais que a mulher no campo grite por socorro, dificilmente é ouvida. A organização do espaço geográfico no campo, onde as famílias residem distantes umas das outras, a dificuldade de deslocamento, acesso à comunicação, os(as) filhos(as) muitas vezes pequenos e a falta de dinheiro tornam-se empecilhos, dificuldade para buscar outras alternativas (LORENZONI, RODRIGUES E SANTOS, 2021, p. 148).

No vídeo Sozinhas - violência contra mulheres que vivem no campo² há o registro e o depoimento de camponesas que moram no estado de Santa Catarina e foram diuturnamente agredidas fisicamente por seus companheiros com facões, foices e machados. Sofreram estupro, tiveram seus braços quebrados, receberam ameaças, entre outros tipos de violência doméstica que demoraram muito tempo para saírem do âmbito privado e tornarem-se público. O vídeo busca tirar o tema do silenciamento e trazê-lo para o debate, tornando-o visível no cotidiano das camponesas.

A violência doméstica representa a autoridade sobre a mulher por meio da utilização da força física, psicológica ou intelectual contra outra pessoa a fim de constranger, tirar sua liberdade e impedir-Ihe de manifestar sua vontade, por meio de graves ameaças, espancamentos, lesões ou mortes. É um meio de coagir, de submeter. Teles (2003) entende que a violência pode ser compreendia como uma forma de restringir a liberdade de uma pessoa ou de um grupo de pessoas, reprimindo e ofendendo física ou moralmente. Em outras palavras, a violência se trata de uma forma de controle das mulheres, as quais se vêm impedidas de se movimentar para buscar ajuda.

A violência, segundo Minayo (2004), é um tema de saúde pública, visto que está associada à qualidade de vida, sobretudo pelas lesões físicas, psíquicas e morais que acarreta, e pelas exigências de atenção e cuidados dos serviços médico-hospitalares. $\mathrm{Na}$ mesma direção de Minayo, Garcia (2016) descreve a violência contra a mulher como um problema de saúde pública de proporções epidêmicas no Brasil, embora sua magnitude seja, em grande parte, invisível.

Saffioti (2001) discorre a respeito do patriarcado para compreender a violência doméstica, uma vez que esse sistema estrutural representa um regime exclusivo de dominação/exploração das mulheres. Segundo a autora, "este regime ancora-se em uma maneira dos homens assegurarem, para si mesmos e para seus descendentes, os meios necessários à produção diária e à reprodução da vida" (SAFFIOTI, 2001, p. 105). Ou seja,

${ }^{2}$ Disponível em: https://www.youtube.com/watch?v=XEuJ9XT2yX8. Acesso em: 11 jun. 2020. 
solidifica-se uma relação de domínio/exploração para perpetuar a continuidade da espécie humana por meio da exploração do trabalho desenvolvido diariamente pela mulher. Esclarece Saffioti (2004, p. 105), "neste regime, as mulheres são objetos da satisfação sexual dos homens, reprodutoras de herdeiros, de força de trabalho e de novas reprodutoras".

Moreira (2019), no artigo "Violência Doméstica: uma problemática de saúde pública", efetuou um balanço dos atendimentos feitos pelo serviço Central de Atendimento à Mulher - Ligue 180, ofertados pela Secretaria Nacional de Políticas para Mulheres (SNPM), no primeiro semestre do ano de 2016. A autora constatou que 67.962 atendimentos realizados correspondiam à relatos de violência doméstica, sendo: 51,06\% referentes à violência física; $31,1 \%$ de violência psicológica; $6,51 \%$ violência moral; $4,86 \%$ cárcere privado; 4,30\% violência sexual; e 1,93 violência patrimonial.

Em decorrência do patriarcado, a violência doméstica é perpetrada por quem a mulher nutre afeto, isto é, seu companheiro, marido ou namorado. Dentre as inúmeras situações de violência que vitimam as mulheres, destacam-se as ocorridas no espaço socialmente definido às mulheres, isto é, o espaço privado, a família e o domicílio, em sua grande maioria (SANTI et al., 2010). Em uma contribuição ao IPEA, Cíntia Liara Engel, em "A violência contra a Mulher" (s/d), identificou que a maior parte das agressões contra mulheres é perpetrada por pessoas conhecidas, cônjuges e ex-cônjuges, e parentes; somadas, a agressões por esse grupo representam quase $70 \%$ dos casos. Ainda, que mais da metade de todas as violências domésticas cometidas contra as mulheres ocorreram em sua própria casa.

No caso do município pesquisado, há a vantagem de existir um CREAS que realiza o atendimento das vítimas. A literatura a respeito do tema, por sua vez, indica que em muitos municípios pequenos que atendem as áreas rurais há precariedade da Rede de Atendimento e Assistência às vítimas de violência, o que dificulta ainda mais esse processo de denúncia dos agressores e cuidado das vítimas (RIEG, CHERFEM, 2019). Contudo, mesmo existindo o serviço, ainda é pouco acessado pelas camponesas.

Em Laranjeiras do Sul (PR), a violência doméstica é um tema silenciado e invisibilizado, seja pelo sistema patriarcal arraigado nas áreas rurais ou pela falta de informação acerca da violência doméstica e dos sistemas de proteção às mulheres. As camponesas têm dificuldades em realizar uma denúncia, seja pela carência de uma cultura de busca por atendimento, seja pela falta de aparato do Estado, ou por conta da própria condição de vida, tal como aprofundaremos a seguir. 


\section{VIOLÊNCIA DOMÉSTICA NO CAMPO: SILENCIAMENTO E INVISIBILIDADE EM LARANJEIRAS DO SUL (PR)}

A fim de aprofundarmos tal investigação, realizamos uma pesquisa junto ao Fórum, na $2^{\text {a }}$ Vara Judicial, e junto ao CREAS (Conselho de Referência Especializado de Assistência Social), o qual oferece atendimento psicológico a mulheres vítimas de violência doméstica. Em todos esses espaços predomina a invisibilidade da violência no campo.

Confirmamos que há indicativos de violência doméstica no meio rural, porém, as vítimas não efetuam as denúncias; há o medo, a dependência econômica, a falta de apoio familiar e social, assim como poucas informações. Em Laranjeiras do Sul constatamos que muitas vezes as mulheres demoram em entender a situação de violência em que se encontram e, quando percebem, não sabem a quem recorrer ou como pedir ajuda. Por isso, o empoderamento da mulher do campo, os serviços públicos adequados e a informação sobre os mesmos, além da organização coletiva, são condições sine qua non para que ela tenha coragem de ir à rede de proteção do Estado para denunciar as agressões que vem sofrendo, assim como solicitar proteção e punição ao agressor.

Observamos nas mulheres do campo de Laranjeiras do Sul aspectos fundamentais que se entrelaçam na reprodução do silenciamento: o medo de perder a guarda dos filhos, as condições financeiras frágeis, o desconhecimento da Lei Maria da Penha, a falta de transporte para a cidade, assim como a distância da rede de apoio do Estado. Como muito bem sintetizam Lorenzoni, Rodrigues e Santos (2021, p.152):

A dependência econômica também em alguns casos, serve de empecilho para romper o silêncio e denunciar. Numa condição de não autonomia econômica, uma vez que a renda no campo provêm da comercialização dos produtos, e ainda, o dinheiro fica sob o controle do homem, torna mais difícil para as camponesas visualizarem outros rumos, outras possibilidades. Em nossa experiência no MMC, constatamos inúmeras mulheres com queixas de dores crônicas e outros sintomas, como dificuldade de dormir, nervosismo, depressão, tristezas, problemas digestivos, perda de sangue, gravidez indesejada, entre outros, escondendo situações de violência. Outras revelam que a sobrecarga de trabalho impedem o cuidado com o corpo que passa desapercebido. Se tudo isso não bastasse, a precariedade das unidades de saúde para 0 atendimento adequado às suas necessidades, especificamente no que diz respeito ao atendimento específico, como direitos sexuais e reprodutivos agrava a violência contra as mulheres camponesas, negras e pobres. 
Também realizamos uma pesquisa na Vara Judicial da violência doméstica no Fórum de Laranjeiras do Sul. O Poder Judiciário informou que, em pesquisa realizada no sistema PROJUDI - Vara Criminal, 516 processos ativos relacionados à violência contra a mulher, até 28 de novembro de 2018. Voltamos ao Poder Judiciário, na pesquisa, e em 6 de março de 2020, já eram somados 692 processos ativos de violência doméstica neste Foro. Em um ano e três meses (de 28/11/2018 a 06/03/2020), portanto, foram protocolados mais 176 processos de violência doméstica, em um percentual de acréscimo de 13,41\% nas agressões contra as mulheres. São muitas agressões protocoladas no Poder Judiciário em tão exíguo tempo. Isso sem contar àquelas que não denunciaram seus agressores. Quantas mais serão?

Notamos, contudo, que não há um filtro disponível no Poder Judiciário para diferenciar entre os processos quais os que têm origem na cidade e os do campo, o que também dificulta a pesquisa. Observamos que o Estado não manifesta interesse na diferenciação entre os crimes de violência doméstica que acontecem no campo ou na cidade. Não há separação dos processos judiciais por local (área rural ou urbana) para estimar números e estatísticas desses crimes por territórios, a fim de subsidiar políticas públicas para as camponesas. Isso indica que o campo é negligenciado nas estatísticas capazes de gerar dados e comprovar a necessidade de ampliação dos serviços públicos nos territórios camponeses, quilombolas e indígenas.

Nesse sentido, destacamos a necessidade de amplitude da discussão do tema, buscando romper o modelo estrutural patriarcal e classista que impõe uma série de limites para as mulheres camponesas. Conforme descreve Paulilo (2016), os movimentos sociais das mulheres camponesas se pautaram, inicialmente, na luta para que as esposas fossem consideradas produtoras rurais e não "do lar". Ou seja, buscaram a valorização do trabalho da mulher que era invisibilizado no campo, visto que não eram consideradas como profissionais da agricultura.

Com o decorrer do tempo, as mulheres ampliaram as suas reivindicações iniciais para o âmbito da categoria de gênero, na medida em que, organizadas, observaram que a opressão que sofriam estava pautada em toda a base do patriarcado no campo. Um exemplo disso é que elas não possuíam o acesso à terra, que só era conquistado pelo casamento ou pela herança. No primeiro caso, elas eram invisibilizadas como agricultoras, sem ter autonomia nas terras do marido. No segundo, acabavam vendendo suas terras para os irmãos ou dividindo-as com o marido. 
No Brasil, demorou-se 488 anos para as mulheres terem acessos à terra com a elaboração da Constituição Federal de 1988. Deere (2004) esclarece que os direitos formais das mulheres à terra foram um esforço para acabar com a discriminação contra as mulheres na reforma constitucional de 1988. O crescente consenso, entre todos os movimentos sociais rurais, sobre a importância em assegurar o direito da mulher à terra, junto com um lobby efetivo, encorajou o Estado em 2001 a adotar mecanismos específicos para a inclusão de mulheres na reforma agrária. Heredia (2006) esclarece que a luta das camponesas para ter acesso à terra, como a Marcha das Margaridas, relacionadas com o reconhecimento da mulher rural enquanto trabalhadora na agricultura, incluem vários itens relativos à reforma agrária e ao acesso à terra, que se somam à reivindicação geral da efetiva realização da reforma agrária e incluem questões específicas das mulheres, como as reivindicações de titulação conjunta das terras para homens e mulheres, de prioridade de assentamento das mulheres chefe de família.

Desse modo, as mulheres camponesas passaram a questionar o próprio conceito de agricultura familiar: se a terra é da família, trata-se de uma decisão a ser resolvida no âmbito privado da família. Contudo, essa família é patriarcal, o que garante os direitos de dominação masculina. Logo, tratava-se de questões a serem resolvidas no amplo aspecto da estrutura social dominante masculina, questionada pelo conceito de gênero (PAULILO, 2016).

Com o decorrer do tempo, as mulheres camponesas começaram a ter outras reivindicações com base no gênero, como licença maternidade, creche no campo, direitos da mulher solteira no campo, dos sujeitos LGBT, participação política (MOTA; PAULA, 2012), além do debate em destaque neste artigo, sobre a questão da violência doméstica no campo. Nota-se que a violência está incluída no bojo de lutas históricas das camponesas pela sua existência como sujeitos sociais e de participação política.

No tema da violência doméstica, são recorrentes no campo as tentativas dos homens de isolar a mulher de sua família, de seu círculo de amigos e das pessoas próximas a quem elas poderiam pedir ajuda ou socorro. Além disso, existe a vergonha de ter sido espancadas, de ter seu corpo marcado pela crueldade sofrida, dos comentários alheios e do julgamento da sociedade e de sua família (LORENZONI, 2008, 2020).

Como vimos, soma-se ainda a falta de condições financeiras para mudar de vida, o que condiciona muitas mulheres a ficarem em um relacionamento abusivo, visto que não existe, no meio rural, uma rede estatal de atendimento às mulheres que sofrem violência doméstica. Além disso, moram longe do centro urbano, enfrentam a falta de transporte 
para a cidade e, na maioria das vezes, não possuem carta de habilitação para dirigir automóvel e se deslocar para pedir ajuda (COSTA et al, 2017; DARON, 2009; GROSSI, 2015; LORENZONI, 2008; RIEG, CHERFEM, 2019).

Quando se fala de violência doméstica, é preciso pontuar que ela acontece em relacionamentos abusivos, no campo e na cidade, nos quais o homem entende que detém o poder sobre a mulher e seu corpo, sua mente, suas emoções, seu patrimônio e sua honra ao difamá-la perante seus pares, seus familiares, seus amigos, atingindo sua autoestima. Nesse último caso, trata-se da violência moral referendada como crime na Lei Maria da Penha e no Código Penal, pelo crime de difamação (art.139).

Como detectado na pesquisa em questão, a violência contra a mulher do campo é uma violência invisibilizada por diferentes meios, quais sejam: pela falta de boletins de ocorrência, na delegacia de polícia do município, pela pouquíssima procura por assistência psicológica no CREAS, pelos processos criminais no Foro local, os quais não discriminam a violência doméstica perpetrada no campo ou na cidade, o que impossibilita ter estatísticas a partir do Estado. Elas pouco constam das estatísticas oficiais. Garcia (2016) entende que, por ser uma violência vivenciada no âmbito privado, bem como por ser, normalmente, perpetrada por familiares e conhecidos, as ocorrências não geram atendimentos e não são captadas pelos sistemas de informação, o que resulta em subenumeração dos eventos e reforça a invisibilidade da violência contra a mulher do campo.

É nesse sentido que Medrazi et al (2021) apresenta a importância da organização coletiva das mulheres camponesas para reverter esse quadro de violência e de silenciamento. No relato abaixo, a organização das mulheres pode ser observada como forma de resistência:

São mulheres camponesas que ousam escrever sobre a história e a construção dos mais de 37 anos de movimento, abordando temas como a luta das mulheres camponesas se tornando sujeitas de direitos, a questão das mulheres indígenas, a defesa dos territórios, as ligas camponesas, o antirracismo, a abordagem do feminismo camponês e popular, a questão da agricultura camponesa versus o agronegócio, a resistência das mulheres através da agroecologia, a relação com as sementes, a alimentação saudável, a divisão sexual do trabalho, a economia feminista, o enfrentamento à violência contra a mulher, a diversidade sexual e também a mística feminista, camponesa e popular que é presente no MMC (MEDRAZl et al, 2021, p. 11). 


\section{A VIOLÊNCIA DOMÉSTICA NO CAMPO É CRIME: A LEI MARIA DA PENHA}

Uma pesquisa recente, realizada em Anitápolis (SC) por uma das autoras deste artigo (RIEG, CHERFEM, 2019), evidenciou a falta de informações das mulheres rurais em torno da Lei Maria da Penha no campo. As pessoas entrevistadas sabiam da existência da lei, mas não conheciam o seu critério de prevenção, proteção e punição, tampouco sabiam das várias formas de violência doméstica sofridas pelas mulheres. As rodas de conversa realizadas em Laranjeiras do Sul, em escolas do campo e clubes de mães do meio rural, também revelaram a falta de informação das camponesas em torno da Lei, da multiplicidade de formas de violência e de seus direitos como mulheres.

A Lei n. 11.340/2006, Lei Maria da Penha, foi responsável por criminalizar a violência doméstica no Brasil. Seu nome deve-se a Maria da Penha Maia Fernandes. Ela é uma mulher com graduação em farmácia e bioquímica, pela Universidade Federal do Ceará (UFC). A luta que ela empreendeu por justiça, em 19 anos e 6 meses, fez dela um símbolo de uma vida livre de violência. Essa lei é reconhecida pela Organização das Nações Unidas (ONU) como uma das três melhores legislações do mundo para o enfrentamento da violência contra as mulheres, sobretudo pelo seu caráter de punição, proteção e prevenção da violência.

De acordo com a Lei Maria da Penha, a violência é praticada contra mulheres em razão do gênero, e consiste em ato que lhe cause a morte, lesão, sofrimento psicológico, sexual, dano patrimonial ou moral (BRASIL, 2006). O primeiro crime é a violência física praticada pelo marido, companheiro, namorado ou por alguém do círculo familiar da vítima, gerando a morte ou lesões no corpo da mulher, ofendendo a sua integridade e a sua saúde. Tem como exemplos: tapas, socos, empurrões, pontapés, lesões corporais com enxadas, machados, facas, muitas vezes levando à morte.

O segundo refere-se à violência psicológica, a qual assume a feitura de humilhações, gritos e xingamentos que diminuam a autoestima da mulher, que Ihe causem dano emocional. Podem ser descritos como atribuindo qualificações a ela, aos brados de velha, gorda, imprestável, vagabunda, não sabe cuidar nem dos filhos, nem dos animais que possuímos: "você só me dá despesa"!

O terceiro crime é o da violência sexual, entendida, como ser obrigada a casar com quem seu pai agricultor determinou. Ser obrigada a manter relações sexuais indesejadas, forçadas com seu marido; ter seu corpo violado mediante ameaças; ser obrigada a 
engravidar e a não utilizar métodos contraceptivos, para o homem ter disponível maior mão de obra familiar, para levar adiante o trabalho na roça. Ser contaminada por infecções sexualmente transmissíveis, advindas do marido frequentar prostíbulos existentes perto do local onde moram. Assim, na forma da lei, a violência sexual é tipificada como:

qualquer conduta que constranja a mulher a presenciar, a manter ou a participar de relação sexual não desejada, mediante intimidação, ameaça, coação ou uso da força; que a induza a comercializar ou a utilizar, de qualquer modo, a sua sexualidade; que a impeça de usar qualquer método contraceptivo ou que a force ao matrimônio, à gravidez, ao aborto ou à prostituição, mediante coação, chantagem, suborno ou manipulação; ou que limite ou anule o exercício de seus direitos sexuais e reprodutivos (BRASIL, 2006, art. $7^{\circ}$, inciso III).

O quarto é o crime de violência patrimonial, que consiste na "conduta de retenção, subtração, destruição parcial ou total de seus objetos, instrumentos de trabalho, documentos pessoais, bens, valores e direitos ou recursos econômicos, incluindo os destinados a satisfazer suas necessidades" (BRASIL, 2006, art. 7ํㅜㄹ inciso IV).

No caso das mulheres camponesas, a violência patrimonial se torna evidente na medida em que elas não conseguem conquistar a terra, ou mesmo quando elas não têm o controle do dinheiro advindo do seu trabalho. Muitas vezes as mulheres são obrigadas a utilizar agrotóxicos, sendo impedidas de exercer técnicas como a agroecologia ou a agricultura orgânica, o que poderia servir para a subsistência de sua família ou para a conquista de sua independência econômica (DARON, 2009; GROSSI, 2015; LORENZONI, 2008). Inúmeras vezes é a mulher quem trabalha com as vacas, retirando o leite, ou trabalha nas feiras, porém, é o marido quem recebe o cheque e utiliza o dinheiro proveniente desse labor, ao seu bel prazer. Como descrevem Lorenzoni, Rodrigues e Santos (2021, p. 150): sofremos também "a violência do agronegócio que é a expressão do capitalismo no campo e que tem como consequência a exclusão, a exploração e a violência contra os camponeses, e especialmente as camponesas, já que, como o capitalismo, o agronegócio é patriarcal".

O quinto modo de violência doméstica é a violência moral, que corresponde a qualquer conduta que configure calúnia, difamação ou injúria. Esse crime se configura por meio de ofensas, lesões à honra, à moral e ao prestígio social da mulher, visando a atingi-la de forma a abalar a sua autoestima, sua imagem. A literatura acerca da violência contra a 
mulher do campo também indica esse tipo de violência como algo recorrente no meio rural, na medida em que há uma perpetuação das fofocas e da culpabilização das vítimas (CHERFEM; RIEG, 2019).

Outro crime tipificado é o feminicídio, que se caracteriza na morte intencional de pessoas do gênero feminino, cuja causa do assassinato decorra de questões de gênero. Como consequência de inúmeras manifestações contrárias à violência contra a mulher em

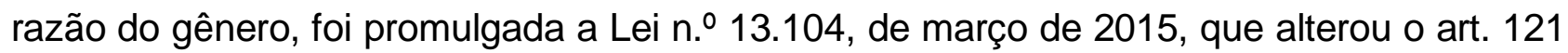
do Código Penal, a qual determina o feminicídio como circunstância qualificadora do crime de homicídio, incluindo-o no rol dos crimes hediondos (BRASIL, 2015).

Em 17 de setembro de 2019, foi novamente atualizada a Lei Maria da Penha,

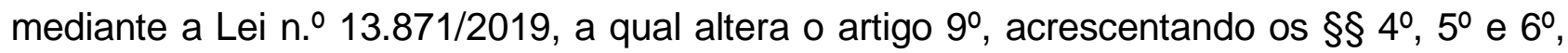
determinando que:

Aquele que, por ação ou omissão, causar lesão, violência física, sexual ou psicológica e dano moral ou patrimonial a mulher fica obrigado a ressarcir todos os danos causados, inclusive ressarcir ao Sistema Único de Saúde (SUS), de acordo com a tabela SUS, os custos relativos aos serviços de saúde prestados para o total tratamento das vítimas em situação de violência doméstica e familiar [...] $\S 5^{\circ}$ Os dispositivos de segurança destinados ao uso em caso de perigo iminente e disponibilizados para o monitoramento das vítimas de violência doméstica ou familiar amparadas por medidas protetivas terão seus custos ressarcidos pelo agressor [...] $\S 6^{\circ}$ O ressarcimento de que tratam os $\S \S 4^{\circ}$ e $5^{\circ}$ deste artigo não poderá importar ônus de qualquer natureza ao patrimônio da mulher e dos seus dependentes, nem configurar atenuante ou ensejar possibilidade de substituição da pena aplicada. (BRASIL, 2019, art. único).

Além disso, a 6 ${ }^{\text {a }}$ Turma do Superior Tribunal de Justiça (STJ) decidiu, em 18 de setembro de 2019, que em caso de afastamento da mulher do seu emprego em virtude de violência doméstica, os primeiros 15 dias devem ser custeados pelo empregador e os demais pelo Instituto Nacional do Seguro Social (INSS). A tese foi levada ao STJ pela Defensoria Pública de São Paulo. Conforme o ministro do STJ, Rogério Schietti Cruz,

Tais situações ofendem a integridade física ou psicológica da vítima e são equiparáveis à enfermidade da segurada, o que justifica o direito ao auxíliodoença, até mesmo porque a Constituição prevê que a assistência social será prestada a quem dela precisar, independentemente de contribuição (CRUZ apud INSS, 2019, p. 1).

Nesse caso, a interrupção do trabalho com a manutenção do vínculo trabalhista se dará por até seis meses. Entende o ministro relator dessa ação no STJ, Rogério Schietti 
Cruz, que "a lei não determinou a quem cabe o ônus do afastamento — se seria responsabilidade do empregador ou do INSS - nem esclareceu se é um caso de suspensão ou de interrupção do contrato de trabalho" (CRUZ apud INSS, 2019, p. 1). Ao justificar a adoção do auxílio doença, Cruz afirmou que:

A vítima de violência doméstica não pode arcar com danos resultantes da imposição de medida protetiva em seu favor. Ante a omissão legislativa, devemos nos socorrer da aplicação analógica, que é um processo de integração do direito em face da existência de lacuna normativa (CRUZ apud INSS, 2019, p. 1).

O órgão colegiado do STJ decidiu também que, "para comprovar a impossibilidade de comparecer ao local de trabalho, em vez do atestado de saúde, a vítima deverá apresentar o documento de homologação ou a determinação judicial de afastamento em decorrência de violência doméstica" (INSS, 2019, p. 1). Os ministros estabeleceram, ainda, que a empregada terá direito ao período aquisitivo de férias, desde o afastamento — que, segundo a própria lei, não será superior a seis meses.

Quanto ao ônus da medida protetiva, o Ministro Rogério Schietti Cruz ressaltou que o legislador não incluiu o período de afastamento previsto na Lei Maria da Penha entre as hipóteses de benefícios previdenciários listadas no artigo 18 da Lei 8.213/1991 (BRASIL, 1991), o que deixou as vítimas de violência desamparadas.

Assim sendo, cabe destacar que a necessidade de criação de uma lei faz parte da construção social das relações de gênero que afetam homens e mulheres e visam preservar vidas, no sentido físico e emocional. Nota-se que essas informações em torno da Lei Maria da Penha são de extrema relevância para proteger as mulheres vítimas de violência, mas, na maioria dos casos, elas não chegam às mulheres camponesas.

\section{MASCULINIDADE TÓXICA, MACHISMO E PATRIARCADO}

Como observado ao longo deste artigo, as diversas formas de violência contra as camponesas têm origem na sociedade patriarcal que compreende a mulher como propriedade privada dos homens. No meio rural, o machismo se perpetua no cotidiano familiar, na medida em que há uma naturalização do mando masculino em detrimento da submissão e dependência feminina (MEDRAZI et al, 2021), além da exploração das mulheres na perpetuação da divisão sexual do trabalho. 
Seja no campo ou na cidade, os meninos aprendem desde cedo que homem "tem que engolir o choro", não pode demonstrar sentimentos, sendo proibidos de brincar de bonecas e com outros brinquedos que ensinam e qualificam para o trabalho de cuidado do outro. Assim, eles aprendem que o serviço doméstico e de cuidado é naturalmente feminino; ele deve ser o bruto, que representa a força física, sem demonstrar sentimentos, nem emoções, aquele que deve estar sempre pronto para o sexo.

Segundo Cisne e Falquet (2020), os homens são constantemente educados para a guerra e para a luta, ou seja, para a violência com o outro e entre eles mesmos. Nas palavras das autoras,

Os corpos masculinos e/ou racializados são compulsoriamente empurrados à guerra e à segurança. Esses "homens armados" geram violência diária que mantém as "mulheres de serviço" em uma situação de precariedade e permanente excesso de trabalho. Ao mesmo tempo, garantem uma direta utilidade/reforço à economia do capital, para reconstruir o que eles constantemente destroem (CISNE, FALQUET, 2020, p. 432).

O documentário denominado Masculinidade tóxica, violência doméstica e machismo - Quebrando o Tabu ${ }^{3}$ foi desenvolvido por uma iniciativa da plataforma Papo de Homem e possui conteúdo crítico a respeito da masculinidade. Esse vídeo demonstra a forma como são educados os meninos, com o fim de silenciá-los por toda a vida, tendo que cumprir os mandamentos da masculinidade, como ser bem sucedido profissionalmente, não levar desaforo para casa, "dar em cima" de todas as mulheres possíveis, enfim, ser "o macho alfa".

Desse modo, origina-se o machismo revelado pela crença da superioridade do gênero masculino sobre o feminino, com desprezo e subjugação do mundo das mulheres. Minayo (2005) entende que o macho social tem suas atitudes e relações violentas como atos corretivos, não reconhecendo seus excessos. Porém, é importante destacar que o machismo e a masculinidade tóxica têm suas origens no patriarcado. Para Saffioti (2001), na função patriarcal cabe aos homens designar e estabelecer normas e punições, ainda que não haja, por parte das vítimas, a tentativa de driblar caminhos diferentes aos regidos pelas normas sociais.

A partir da instituição da estrutura do patriarcado, as mulheres foram submetidas ao poder masculino, passando a serem agredidas e a terem seus direitos violados (psíquicos, morais, físicos, patrimoniais e sexuais). Para Castells (2010, p. 169), "os relacionamentos

${ }^{3}$ Disponível em: https://www.youtube.com/watch?v=uiFjHFeqsM0.Acesso em: 11 jun. 2020. 
interpessoais e, consequentemente, a personalidade, também são marcados pela dominação e violência que têm sua origem na cultura e instituições do patriarcalismo".

Hoje, o trabalho das camponesas é um dos pilares essenciais da agricultura familiar. Shanin (2005) explica que a economia dos camponeses se verifica pelo trabalho familiar, em uma economia de subsistência, possuindo o controle dos meios de produção, com ênfase no cultivo. Para esse autor, a economia camponesa é caracterizada pelo trabalho permanente e necessário da mulher, do homem e da prole. Contudo, na prática, esse trabalho realizado pelas mulheres continua sendo desvalorizado e considerado como "ajuda" (PAULILO, 2016), o que impede a emancipação das mulheres camponesas, dificultando, sobretudo, a reação quando acometidas pela violência.

Conforme destacado ao longo desse artigo, nos espaços informais dos grupos em Laranjeiras do Sul, as mulheres revelam a violência que sofrem silenciadas e que muitas vezes nem percebem como violência, uma vez que o patriarcado no campo vem se perpetuando como ideologia dominante e não questionada. Paralelamente, os homens camponeses, aos poucos, começam a refletir sobre esse padrão de masculinidade associado à violência, o que se dá por meio da movimentação e organização das mulheres, como revelam o MMC e os setores de gênero do MST (MEDRAZI et al, 2021).

Wanderley (2014) esclarece que o campesinato é uma forma social de produção baseada no caráter familiar, voltada às necessidades da família, que pressupõe a cooperação de seus membros, mas que precisa romper a base patriarcal. É um modo de viver e trabalhar no campo que corresponde a um modo de vida e a uma cultura, logo, deveria ser igualitário para homens e mulheres.

Dessa forma, a mulher camponesa se encontra presente em todas as fases da produção agrícola. Ela semeia, limpa a área, colhe os produtos, mantém os quintais produtivos, preserva as sementes que proporciona a agroecologia, porém seu trabalho é visto como um apêndice. Somado a isto, é ela quem cuida da casa, dos filhos, das roupas, dos animais. Ela cultiva as ervas medicinais para os cuidados nas doenças e preservação e reprodução da vida no campo.

Porém, mesmo tendo tantas responsabilidades na vida e na produção familiar, faz-se necessário romper o ciclo de violência ainda sofrida, o silenciamento contra todas as formas de violações e opressões enfrentadas, a falta de dados no tocante à violência doméstica perpetrada contra as mulheres camponesas, a fim de construir novas possibilidades de relações sociais que humanize homens e mulheres, do campo e da cidade. 


\section{CONSIDERAÇÕES FINAIS}

Este trabalho foi realizado com o objetivo de pesquisar o tema da invisibilidade da violência doméstica no campo, tema pouco presente na academia e que vem ganhando força nos movimentos de mulheres camponesas. Foi efetuada uma pesquisa no Superior Tribunal de Justiça (STJ - 6 Turma), na legislação brasileira, em bibliografia da área e de análise documental dos dados no Fórum de Laranjeiras do Sul e no Conselho de Referência Especializado de Assistência Social do Município, a respeito dos atendimentos psicológicos efetuados.

O resultado aponta para a existência invisibilizada e calada da violência doméstica no meio rural, das quais padecem as camponesas. A pesquisa revelou como esses crimes são guardados silenciosamente pelas mulheres que sofrem violência no campo, sozinhas e distantes. Observa-se o pequeno número de camponesas que procuram o apoio do serviço psicológico do CREAS na questão da violência doméstica, assim como os números escassos de Boletins de Ocorrência, na Delegacia de Polícia do Município.

Os números de processos judiciais no Fórum de Laranjeiras do Sul (516 ativos em 28/11/2018 e 692 em 06/03/2020) demonstram alguma mobilização das mulheres frente aos seus agressores, no sentido de procurar o Poder Público, mais especificamente o Poder Judiciário, no âmbito criminal, para denunciar os crimes de violência doméstica, assim como pedir medidas protetivas contra seus agressores. No interstício de 15 meses, houve um aumento de $3 \%$ nos processos judicializados pela Lei Maria da Penha, neste município.

Porém, o Estado não disponibiliza a diferenciação entre processos do meio rural e do meio urbano, o que dificulta a compreensão em torno da necessidade de realizar políticas públicas específicas para as mulheres camponesas. No CREAS começam a aparecer em poucas, mas significativas presenças, as primeiras mulheres camponesas que procuram atendimento psicológico gratuito por causa da violência doméstica (percentual de 7,82 \% dos atendimentos entre 2016 a 2018). São poucos atendimentos, mas já indicam um início de comportamento reativo frente aos agressores e às situações vivenciadas.

A luta das camponesas que sofrem violência doméstica é árdua, com um quinhão de coragem superior à vida urbana dada as dificuldades que enfrentam: falta de transporte, falta de delegacias da mulher nas proximidades, falta de atendimento especializado (psicólogos e assistentes sociais), falta de uma rede de proteção às mulheres vítimas de 
violência doméstica no campo, falta de transporte, assim como as dificuldades financeiras e o medo de perderem o seu trabalho no campo.

Além disso, identificamos que há o medo de perderem os filhos, de não poderem voltar para a casa dos pais, de serem assassinadas e de não conseguirem refazer suas vidas. Desse modo, a pesquisa realizada deverá ser aprofundada no município, buscando contribuir com a visibilidade dessas situações e com o rompimento desse ciclo na vida das camponesas. Ao mesmo tempo, pretendemos avançar nas pesquisas realizadas nas zonas rurais devido a sua relevância social e potencial de contribuição para ampliar o debate científico acerca da violência silenciada contra a mulher do campo.

\section{REFERÊNCIAS}

BRASIL. Lei no 13.871/2019. Altera a Lei no 11.340, de 7 de agosto de 2006 (Lei Maria da Penha), para dispor sobre a responsabilidade do agressor pelo ressarcimento dos custos relacionados aos serviços de saúde prestados pelo Sistema Único de Saúde (SUS) às vítimas de violência doméstica e familiar e aos dispositivos de segurança por elas utilizados. Brasília, DF: Presidência da República, 2019. Disponível em: http://www.planalto.gov.br/ccivil 03/ ato2019-2022/2019/lei/L13871.htm. Acesso em: 22 set. 2019.

BRASIL. Lei no 13.104/2015. Altera o art. 121 do Decreto-Lei $n^{\circ} \mathbf{2 . 8 4 8}$, de 7 de dezembro de 1940 - Código Penal, para prever o feminicídio como circunstância qualificadora do crime de homicídio, e 0 art. 1ํ da Lei $n^{\circ}$ 8.072, de 25 de julho de 1990, para incluir 0 feminicídio no rol dos crimes hediondos. Brasília, DF: Presidência da República, 2015. Disponível em: http://www.planalto.gov.br/ccivil 03/ Ato2015-2018/2015/Lei/L13104.htm. Acesso em: 18 set. 2019.

BRASIL. [Lei Maria da Penha]. Lei no 11.340/2006. Coíbe a violência doméstica e familiar contra a mulher. Brasília, DF: Presidência da República, 2006. Disponível em: http://www.planalto.gov.br/ccivil 03/ ato2004-2006/2006/lei//11340.htm. Acesso em: 19 set. 2019.

BRASIL. Lei no 8.213/1991. Dispõe sobre os Planos de Benefícios da Previdência Social e dá outras providências. Brasília, DF: Presidência da República, 1991. Disponível em: http://www.planalto.gov.br/ccivil 03/leis//8213cons.htm. Acesso em: 25 set. 2019.

CARISSIMI, Fabrícia Santina de Oliveira. Movimentos sociais e a violência contra as mulheres do campo: (in)certezas de uma trajetória. Seminário Internacional Fazendo Gênero 10 (Anais Eletrônicos), Florianópolis, 2013. ISSN2179-510X.

CASTELLS, Manuel. O poder da identidade. São Paulo: Paz e Terra, 2010. 
CISNE, Mirla; FALQUET, Jules. Economia política sob uma análise feminista materialista: a imbricação das relações sociais de sexo, raça e classe. SERV. SOC. REV., LONDRINA, V. 22, N.2, p. 425-440, 2020.

COSTA, Marta Coco da et al. Mulheres rurais e situações de violência: fatores que limitam - acesso e a acessibilidade à rede de atenção à saúde. Revista Gaúcha de Enfermagem, Porto Alegre, v. 38, n. 2, 2017. Disponível em: https://doi.org/10.1590/19831447.2017.02.59553. Acesso em: 12 jun. 2020.

DARON, Vanderleia L. P. Um Grito Lilás: Cartografia da Violência às Mulheres do Campo e da Floresta. Brasília: Secretaria de Políticas para as Mulheres, 2009. Mimeografado.

DEERE, Carmen Diana. Os direitos da mulher à terra e os movimentos sociais rurais na reforma agrária brasileira. Rev. Estud. Fem. vol.12 no.1 Florianópolis Jan./Apr. 2004

ENGEL, Cíntia Liara. A Violência contra a Mulher. IPEA. Disponível em: https://www.ipea.gov.br/retrato/pdf/190215_tema_d_a_violenca_contra_mulher.pdf. Acesso em 23/05/2021.

GARCIA, Leila Posenato. A magnitude invisível da violência contra a mulher. Epidemiol. Serv. Saúde, Brasília, v. 25, n.3, jul./set., 2016.

GROSSI, Patricia Krieger et al. O ENFRENTAMENTO DA VIOLÊNCIA CONTRA A MULHER RURAL: desafios para as políticas públicas. VII Jornada Internacional de Políticas Públicas, São Luís, $2015 . \quad$ Disponível em: http://www.joinpp.ufma.br/jornadas/joinpp2015/pdfs/eixo7/o-enfrentamento-da-violenciacontra-a-mulher-rural-desafios-para-as-politicas-publicas.pdf. Acesso em: 12 jun. 2020.

HEREDIA, Beatriz Maria Alásia. Gênero e acesso a políticas públicas no meio rural brasileiro. REVISTA NERA - ANO 9, N. 8 - JANEIRO/JUNHO DE 2006 - ISSN 18066755

INSS deve custear afastamento de mulher ameaçada de violência doméstica. Revista Consultor Jurídico, 2019. Disponível em: https://www.conjur.com.br/2019-set-18/insscustear-afastamento-mulher-ameacada-violencia. Acesso em: 12 jun. 2020.

LORENZONI, Carmem et al. Chega de violência contra a mulher: rompendo o silêncio em defesa da vida. $2^{\underline{a}}$ ed. Passo Fundo: Batistel, 2008.

LORENZONI, Carmen. Violência nas relações de gênero e classe; Uma interpretação a partir das mulheres camponesas do Rio Grande do Sul. Libertas, Juiz de Fora, 2007. Disponível em: https://periodicos.ufjf.br/index.php/libertas/article/view/18218. Acesso em: 12 jun. 2020.

LORENZONI, Carmem; RODRIGUES, Sandra Marli da Rocha; SANTOS, Sirley Ferreira dos. Enfrentamento à violência contra a mulher. In MEDRAZI, Adriana Maria et al. (orgs.). Feminismo Camponês Popular. Reflexões a partir de experiências no Movimento de Mulheres Camponesas. São Paulo: outras expressões, 2020. 
MEDRAZI, Adriana Maria et al. (orgs.). Feminismo Camponês Popular. Reflexões a partir de experiências no Movimento de Mulheres Camponesas. São Paulo: outras expressões, 2020.

MOREIRA, lara Duarte; PÔNCIO, Thiara Guimarães Heleno de Oliveira; DAMASCENO, Márcio Rocha. VIOLÊNCIA DOMÉSTICA: UMA PROBLEMÁTICA DE SAÚDE PÚBLICA. V Seminário Científico do UNIFACIG - 07 e 08 de novembro de 2019 IV Jornada de Iniciação Científica do UNIFACIG - 07 e 08 de novembro de 2019.

MINAYO, Maria Cecília de Souza. A difícil e lenta entrada da violência na agenda do setor saúde. Cad. Saúde Pública, Rio de Janeiro, v. 20, n. 3, p. 646-647, maio/jun. 2004.

MINAYO, Maria Cecília de Souza. Laços perigosos entre machismo e violência. Ciênc. saúde coletiva, Rio de Janeiro, v.10, n.1, jan./mar. 2005.

MOTA, Maria Eleusa da; PAULA, Maysa do Carmo de. A questão de gênero no MST e a educação do campo. Rev. Ed. Popular, Uberlândia, v. 11, n. 2, p. 70-82, jul./dez. 2012.

PAULILO, Maria Ignês. Mulheres Rurais: quatro décadas de diálogos. Editora UFSC: Florianópolis, 2016.

RIEG, Cristiane. Floriano; CHERFEM, Carolina Orquiza. Violência contra as mulheres do campo a partir do município de Anitápolis-SC: uma história silenciada. In: Grazielly Alessandra Baggenstoss (et al) (orgs.). Não há lugar seguro: estudos e práticas sobre violências contra as mulheres à luz da multidisciplinariedade. $1^{\underline{a}}$ ed. Florianópolis: Editora Centro de Estudos Jurídicos (CEJUR), 2019, v. 2, p. 300-318.

SAFFIOTI, Heleieth I. B. Contribuições feministas para o estudo da violência de gênero. Cadernos Pagu, Campinas, n. 16, p. 115-136, 2001. Disponível em: https://doi.org/10.1590/S0104-83332001000100007. Acesso em: 12 jun. 2020.

SANTI, Liliane Nascimento de; NAKANO, Ana Maria Spanó; LETTIERE, Angelina. Percepção de mulheres em situação de violência sobre o suporte e apoio recebido em seu contexto social. Texto \& Contexto Enfermagem, Florianópolis, v. 19, n. 3, p. 417424, 2010.

SILVA, Alessandra Keila. FEMINISMO CAMPONÊS E POPULAR: A CONSTRUÇÃO DA IDENTIDADE FEMINISTA DAS MULHERES DO MOVIMENTO DE MULHERES CAMPONESAS DE ALAGOAS. Cadernos de Agroecologia - ISSN 2236-7934 - Anais do 3o Colóquio Internacional Feminismo e Agroecologia - Vol. 15, № 3, 2020

SHANIN, Teodor. A definição de camponês: conceituações e desconceituações - o velho e o novo em uma discussão marxista. Revista Nera, Presidente Prudente, ano 8, n. 7, p. 1-21, jul./dez. 2005.

TELES, Maria Amélia de Almeida; MELO, Mônica de. O que é violência contra a mulher. São Paulo: Brasiliense, 2003.

WANDERLEY, Maria de Nazareth B. O campesinato brasileiro: uma história de resistência. Rev. Econ. Sociol. Rural, Brasília, v. 52, supl.1, 2014. 


\section{NOTAS}

\section{Maria Eloá Gehlen}

Doutora em Educação

Universidade Federal da Fronteira Sul, Laranjeiras do Sul, Brasil.

maria.gehlen@uffs.edu.br

Ohttps://orcid.org/0000-0003-3802-9434

\section{Carolina Orquia Cherfem}

Doutora em Ciências Sociais da Educação

Universidade Federal de Santa Catarina, Florianópolis, Brasil.

carolina.cherfem@ufsc.br

(Dhttps://orcid.org/0000-0003-1482-7298

Endereço de correspondência do principal autor

Rua Marechal Cândido Rondon, 1332, bairro Água Verde, 85.302-090, Laranjeiras do Sul, PR, Brasil.

\section{CONTRIBUIÇÃO DE AUTORIA}

Concepção e elaboração do manuscrito: M. E. GEHLEN, C. O. CHERFEM

Coleta de dados: M. E. GEHLEN

Análise de dados: M. E. GEHLEN, C. O. CHERFEM

Discussão dos resultados: M. E. GEHLEN, C. O. CHERFEM

Revisão e aprovação: M. E. GEHLEN, C. O. CHERFEM

\section{CONJUNTO DE DADOS DE PESQUISA}

Todo o conjunto de dados que dá suporte aos resultados deste estudo foi publicado no próprio artigo.

\section{FINANCIAMENTO}

Não se aplica.

\section{CONSENTIMENTO DE USO DE IMAGEM}

Não se aplica.

\section{APROVAÇÃO DE COMITÊ DE ÉTICA EM PESQUISA \\ Não se aplica.}

\section{CONFLITO DE INTERESSES}

Não se aplica.

\section{LICENÇA DE USO - uso exclusivo da revista}

Os autores cedem à Revista Internacional Interdisciplinar INTERthesis os direitos exclusivos de primeira publicação, com o trabalho simultaneamente licenciado sob a Licença Creative Commons Attribution (CC BY) 4.0 International. Estra licença permite que terceiros remixem, adaptem e criem a partir do trabalho publicado, atribuindo o devido crédito de autoria e publicação inicial neste periódico. Os autores têm autorização para assumir contratos adicionais separadamente, para distribuição não exclusiva da versão do trabalho publicada neste periódico (ex.: publicar em repositório institucional, em site pessoal, publicar uma tradução, ou como capítulo de livro), com reconhecimento de autoria e publicação inicial neste periódico.

PUBLISHER - uso exclusivo da revista

Universidade Federal de Santa Catarina. Programa de Pós-graduação Interdisciplinar em Ciências Humanas. Publicação no Portal de Periódicos UFSC. As ideias expressadas neste artigo são de responsabilidade de seus autores, não representando, necessariamente, a opinião dos editores ou da universidade.

EDITORES - uso exclusivo da revista

Javier Ignacio Vernal, Silmara Cimbalista e Selvino José Assmann (In Memoriam).

EDITOR ASSISTENTE: Eixo temático: (Re)discutindo sexualidade: corpo, prazer e desejo em tempos conservadores

Luiz Barp

HISTÓRICO - uso exclusivo da revista

Recebido em: 30-06-2020 - Aprovado em: 30-05-2021 - Publicado em: 05-06-2021 